\title{
The Ashgate Research Companion to Contemporary Religion and Sexuality
}

STEPHEN J. HUNT \& ANDREW K.T. YIP, 2012

Farnham, Surrey \& Burlington, CT: Ashgate

336 pp., £90.00, US\$149.95 (hb)

ISBN 978-1-4094-0949-6 (hb), ISBN 978-1-4094-0950-2 (eb)

In their timely and important volume, editors Stephen Hunt and Andrew Yip bring together the important sociological constructs of religion and sexuality, acknowledging and exploring the inherent diversity that characterises them. One of the many impressive and commendable aspects of this research companion lies in the deliberate focus on the diverse range of religious traditions, which have hitherto been ignored in comparable volumes. These include Hinduism, Islam, and Buddhism. Moreover, there is attention to a range of sexual identities and an acknowledgement of the fluidity of the taken-for-granted sexual categories. The collection neatly weaves together methodological concerns, substantive contributions to the field, theoretical development and, most notably, epistemological debates. It is rare to find a volume that explicitly and elaborately focuses on multiple levels of analysis (the social, spiritual, and institutional).

As a social psychologist, I would like to have seen more coverage of psychological approaches focusing on the position of the individual in relation to his/her social group memberships and society more generally. The individual is often forgotten in sociological work, but this volume includes implicit coverage of the individual as a social being. Although the primary focus is on the field of sociology—both editors are sociologists—the volume's 
themes go far beyond sociological enquiry and ambitiously integrate diverse disciplinary approaches, including philosophy, theology, and anthropology.

Part One covers epistemological and methodological issues underpinning religion and sexuality research. Susannah Cornwall (chapter 1) examines Abrahamic religious epistemologies of sexuality and gender and observes commonalities among the three Abrahamic faiths, particularly in reference to "their trend for resisting" (27) in the context of dogma. There is an optimistic vision for the future, with the author implicitly contesting some of the more essentialist accounts of religion and sexuality. Similarly, Lisa Isherwood (chapter 2) presents a feminist critique of sexuality and religion, lamenting that "there are heteropatriarchal assumptions underpinning the construction of religion and sexuality/gender" (31). Conversely, feminist theology is said to emphasise the experiential aspects of religion and sexuality, which seems an appealing approach to scholars interested in lived experience. I would have welcomed some clearer insight into how this approach may be deployed in empirical research.

Olu Jenzen and Sally Munt (chapter 3) present a fascinating account of queer theory, religion, and sexuality and approach concerns that I have encountered in my own research into experiences of religious sexual beings in the predominantly secular LGBT space (Jaspal and Cinnirella). The authors argue that the "LGBT movement has also actively sought to re-inscribe religious rituals and practices with positive, inclusive meanings" (55) in order to gain access to religion in a way commonly thought impossible. Dominant social representations of religion among LGBT groups suggest that religion is a source of homophobia and oppression. Yet, LGBT individuals of faith clearly articulate religious identities. Asifa Siraj (chapter 4) describes how her 
identity as a heterosexual practising Muslim who wears the hijab may have shaped both her approach to her research topic and her analysis of the data. This chapter chimes with my own research (e.g. Jaspal), also with regard to the reciprocal process of my own identity and heuristic framework shaping the interpretation of data and research in turn changing my ways of thinking and aspects of my identity. This chapter could have been bolstered by considering how the author, as 'Other' to her research community, may have been changed by her research.

Part Two on "Religious Texts" reminded me Yip's splendid article on "queering religious texts" in relation to LGBT Muslims' engagement with Scripture (Yip). Adrian Thatcher (chapter 5) refers to the reader of the Bible or any religious scripture as 'coping' with inherent ambiguities and apparent discontinuities. I would agree wholeheartedly with Thatcher that human beings seek to cope with ambiguity, given their desire for clarity, meaning, and certainty. Thatcher echoes the notion of an acceptance strategy that has been described in social psychology: in the face of discontinuity and ambiguity, what is required is "not denial, but ingenious engagement" and a "re-reading in the light of the work of the eternal God" (89). Jan Anderson (chapter 6), writing on diversity versus uniformity in Roman Catholic priesthood, develops some of the ideas highlighted in the preceding chapter but her focus is on identity and the alleged clash of identities. She argues that distinct groups have constructed separate identities on the basis of notions of celibacy and sexually intimate friendship, elegantly showing the constructedness of identity and the rhetorical aspects of its construction.

Dervla Shannahan (chapter 7) questions the notion of Islam being necessarily opposed to homosexuality, as often claimed in reference to Islamic 
theological sources, and provides important insights regarding the emerging reverse discourse concerning the Islamic stance(s) on homosexuality and LGBT identities (e.g. Kugle). Shannahan outlines some possibilities for queer culture afforded by the queer (re-)negotiation of Islam. Kustiani Kustiani and Hunt (chapter 8) discuss the "radical departure that Buddhism appears to make in evaluating menstruation" (123), viewing it as a 'normal' and natural physical process rather than warranting stigma, as other religions append taboos to menstruation and sexual activity during menstruation. The authors highlight the impact of cultural influences on the stigmatisation process.

Part 3 engages with the treatment of sexuality in institutional contexts. Anouka van Eerdewijk (chapter 9) discusses the negotiation of pre-marital sex in Dakar (Senegal), elegantly examining issues of power, gender, labelling, and other anthropological aspects of sexuality. One of her key contributions is the stark reminder of the fluidity of categories and identities that are deployed, (re-)negotiated, and embraced with varying social outcomes. Such issues are reiterated by Fida Sanjakdar (chapter 10) who focuses on religion and sexuality in Islamic educational contexts, noting the potential difficulties associated with delivering sexuality education in Islamic schools in the West given associated contestation and powerful emotions. One response has been a silencing of sex in schools and shame at its invocation. In her qualitative study of Australian Islamic schools, Sanjakdar demonstrates how teachers may both challenge power structures and inadvertently perpetuate particular ideologies. Far from providing clear-cut answers, she presents a useful discussion of the inherent social challenges of sex education in schools.

Michael Keenan (chapter 11) presents a fascinating account of gay clergymen's negotiations with the institutional church, which acknowledges 
homosexuality but may reject the notion of 'sexually active' homosexuality. Arguing that gay clergy manage potential tensions between the 'call to vocation' and their perceived lack of acceptance in religious community, Keenan alludes to the social psychological themes of cognitive dissonance, psychological coherence, and identity integration. Drawing upon Goffman's work, Keenan argues that clergymen may separate God and Church in order to "focus on felt acceptance from God, rather than public experiences of rejection" (185). Using qualitative and quantitative evidence, Alex Toft (chapter 12) discusses similar themes in negotiating bisexuality and Christianity in church life. The separation, at least at psychological level, of institutional religion and spirituality facilitated a sense of identity integration and church attendance was not seen as guiding religious life, which allowed bisexual Christians to maintain a coherent identity.

The focus of Part 4 is on stability and change, with preceding chapters having laid the groundwork for this section. David Richards (chapter 13) examines contemporary religious opposition to gay rights and feminism, especially from the Christian tradition, presenting a meticulous account of both theological and historical perspectives. While not everybody will agree with his anti-patriarchal reading of Christianity, his argument is compelling. Hunt's contribution (chapter 14) on religious discourse and the legitimacy of non-heterosexuality is important, because of the lack of knowledge about Hinduism's (theological) 'stance' on sexual orientation and the profound social and political changes in sexuality in India. Two points are particularly noteworthy: the politicisation of non-heterosexuality on the political right and the inherent diversity of Hinduism which makes discussions about sexuality from the viewpoint a unitary religious ideology difficult. Heather White 
(chapter 15) discusses the under-explored topic of sexual identity construction in faith-based abstinence movements, providing a thought-provoking look at the complex origins of these movements and the paradoxes that characterise their existence and laying the groundwork for future empirical research among members of such groups.

Sarah Page, Yip, and Keenan (chapter 16) explicitly focus on underexplored faith groups regarding religious and sexual identity negotiation. Combining qualitative with quantitative methods, they argue that the young adults in their project "were often negotiating past, present and future in order to reach a successful end-point on their sexual and religious journeys" (268). The authors capture what many studies fail to acknowledge: the centrality of change in identity construction and management, which the authors attempt to accentuate in relation to young people's meaning making of their sexual identities. Moreover, the acknowledgement of emotion, particularly fear, in relation to future identities is interesting, adding a further layer of complexity to identity integration.

Part 5 engages with ways of contesting hegemonic structures and discourses in order to construct coherence between religion and sexuality, nicely bringing together important issues and levels of analysis discussed in preceding chapters. Orit Avishai (chapter 17) argues that "practices, regulations and narratives that appear to be sex-constraining and sex-negative may be potentially experienced as neutral or even sex-positive" (275), focusing on Jewish laws of menstrual purity. Like other authors in the volume, Avishai successfully demonstrates the dangers of essentialism, such as the perception that religious laws are set in stone and thus inhibit rather than facilitate sexual identities. She notes that the practice of niddah allows 
women to "resist, rebel or find liberatory potential within the system" (286) and, as a controversial construct, niddah opens up debate, thereby opening new avenues and future possibilities. Simon Theobald (chapter 18) discusses innovative ways in which Orthodox Jews attempt to explore and take control of their sexuality, amid the discernible stigma of overt sexual practice and desire in Orthodox circles. The focus is on the opportunities afforded by the Internet and other technologies. Theobald's coverage of some of the methodological problems associated with both Internet and Orthodox Jewish communities is interesting and conducive to reflection on the practicalities and complexities of conducting sensitive research of this kind. Melissa Wilcox (chapter 19) examines how queer Christians in the US negotiate religious and sexual identities, focusing on the tendency to challenge heteronormativity and to reinscribe 'homonormativity'. Using the Sisters of Perpetual Indulgence as an example, Wilcox shows how they create 'space' for religious selfidentification, even if they do not gain enough political clout to effect greater social acceptance. This chapter invokes similarities between the three Abrahamic faiths, elucidating interesting paths for future research.

Finally, Amanullah De Sondy (chapter 20) explores Islamic masculinities through the Koranic Adam, arguing that, while not providing clear answers, scripture should be considered a vehicle for "believers to delve into the grey area of confusion in order to strengthen and challenge their belief" and that there has been widespread opposition to "creativity and independent thoughts surrounding prophetic lives" (319). The analysis of various narratives within the Koran is insightful and provides a fresh contribution to an area that seldom receives attention. 
In summary, this is volume is wholeheartedly recommended. It is ambitious, wide-ranging, and genuinely multidisciplinary. It does not shy away from controversial issues and actively promotes debate in hitherto under-explored areas in religion and sexuality. These are the ingredients required to initiate sensible discussions about the interface of religion and sexuality. While not seeking to provide definitive answers to difficult questions, this companion initiates and encourages debate of these questions. The authors' attention to the various layers of identity is probably the strongest aspect of this collection, with the role of the individual in relation to the social world probably its weakest. Thus future editions of this volume would benefit from broadening this perspective.

RUSI JASPAL

Faculty of Health E Life Sciences, De Montfort University, Leicester, UK

\section{REFERENCES}

Jaspal, Rusi. “Arranged Marriage, Identity and Psychological Wellbeing among British Asian Gay Men." Journal of GLBT Family Studies 10 (2014): $425-48$.

Jaspal, Rusi, and Marco Cinnirella. “Coping with Potentially Incompatible Identities: Accounts of Religious, Ethnic and Sexual Identities from British Pakistani Men who Identify as Muslim and Gay." British Journal of Social Psychology 49 (2010): 849-70.

Kugle, Scott. Homosexuality in Islam: Critical Reflection on Gay, Lesbian, and Transgender Muslims. Oxford: Oneworld, 2010. 
Yip, Andrew Kam-Tuck. “Queering Religious Texts: An Exploration of

British, Non-heterosexual Christians' and Muslims' Strategy of

Constructing Sexuality-affirming Hermeneutics." Sociology 39 (2005): 4765. 